\title{
The role of calcium deposition in the ligamentum flavum causing a cauda equina syndrome and lumbar radiculopathy
}

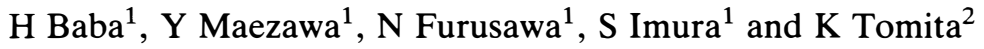 \\ ${ }^{1}$ Department of Orthopaedic Surgery, Fukui Medical School, Shimoaizuki 23, Matsuoka, Fukui 910-11, Japan; \\ ${ }^{2}$ Department of Orthopaedic Surgery, School of Medicine, Kanazawa University, Takaramachi 13-1, Kanazawa \\ 920, Japan
}

Our report concerns five patients who underwent lumbar decompressive surgery for cauda equina syndrome and radiculopathy secondary to degenerative stenosis associated with calcium deposition in the ligamentum flavum. The resected ligamentum flavum showed diffuse to massive calcium crystal deposition with a histologically marked degeneration in the elastic fibres. Energy dispensive radiographic microanalysis confirmed the crystal to be calcium pyrophosphate dihydrate in all patients, hydroxyapatite mixed in three and calcium orthophosphate mixed in one. The deposition appeared to be a change that is associated with the degenerative process in the ligament and, in some cases having marked deposition in a localised event, it causes or aggravates the neurological symptoms

Keywords: lumbar spinal stenosis; cauda equina syndrome; radiculopathy; ligamentum flavum; calcium crystal deposition

\section{Introduction}

A number of reports in the literature describes the anatomical changes in the stenotic lumbar spine which produce the intermittent symptoms of cauda equina claudication and sciatica. ${ }^{1,2}$ The pathoanatomy in the degenerative process includes hypertrophy of the medial portion of the facet joint and the lamina, intervertebral discs bulged posteriorly, narrowing of the neuroforamina, and hypertrophied ligamentum flavum. Ossification and calcification of the ligamentum flavum of the lumbar spine causing neurological compromise are reported to be rare and much is still not known with respect to the possible role of calcium crystal deposition in the ligamentum flavum as observed in symptomatic lumbar spinal stenosis. ${ }^{3-5} \mathrm{We}$ report on five patients who have had marked calcium crystal deposition in the lumbar ligamentum flavum at the surgical site and discuss its possible role in the production of symptoms associated with spinal stenosis.

\section{Patients and methods}

Two hundred and fifty-nine patients with symptomatic lumbar spinal stenosis underwent decompressive laminotomy at our university medical centres between 1986 and 1993. Five patients (2\%) had marked calcium crystal deposition within the ligamentum flavum at the site of the laminotomy. All were women, 59-82 years of age (average, 70 years). Plain radiographs, myelograms, and computed tomographic scans (GE CTT 8800, General Electrics, Milwaukee, WI, USA) demonstrated in all patients that the ligamentum flavum with calcification compressed the dural sac at the levels suspected to be responsible for the cauda equina syndrome and radiculopathy. According to classification of Arnoldi et al, ${ }^{6}$ all patients showed a degenerative type of stenosis radiologically; two had mild spondylolisthesis anteriorly and one had scoliosis. Radiographic examination was selectively performed to investigate calcification at other sites in the lumbar spine. Surgical treatment included a one-level total laminectomy for four patients and a bilateral partial laminectomy for one. In all cases, the dural sac was completely decompressed and nerve root entrapment was completely eliminated, leading subsequently to clinical improvement postoperatively. The postoperative neurological status was assessed as follows: (1) excellent, every preoperative symptom relieved and abnormal findings improved so that the patient could walk without support for more than 500 metres; (2) good, minimal persistence of preoperative symptoms and abnormal findings unchanged or improved, and walking ability improved but restricted up to 500 metres; (3) fair, definite relief of some preoperative symptoms, but other symptoms unchanged or only slightly improved, and walking tolerance with intermittent use of support less than $200 \mathrm{~m}$; and (4) poor, signs and symptoms unchanged or worse. The patients. were followed up for 0.8 to 7 years.

The resected ligamentum flavum was examined histologically (hematoxylin and eosin, and von Kossa's stains), and energy dispensive radiographic microanalysis (Energy Dispensive X-Ray Microanalyzer JDX-8P, Nihon Denshi, Tokyo, Japan) of calcified material was conducted to identify the calcium crystals. 


\section{Results}

\section{Clinical and radiological findings}

Comprehensive data on patient status preoperatively and at the latest hospital visit is given in Tables 1 and 2 . Two patients had hypertension and one had mild diabetes mellitus requiring diet therapy. Calcification at sites other than in the lumbar spine was noted at the shoulder joint in one patient, at the knee meniscus in two, and at the pubic symphysis in one. Subjective symptoms and distinctive findings from L5 radiculopathy were noted in all patients, with neurological intermittent claudication of varying degree in four patients. One patient (case 5) was unable to walk because of intractable pain in the right thigh.

Calcium crystal deposition was observed at the L3-4 level in one, the L4-5 level in all, and the L5-S1 level in two. Myelograms showed an hour-glass constriction of the dural sac at the corresponding levels of varying degrees: (1) a severe total block below the puncture site in three (cases 1, 3 and 4), and (2) a partial block with the scanty passage of contrast medium in two (Figure 1 ). The calcium was deposited diffusely in the ligamentum flavum in all patients but, in case 4 , the mass was observed as seen in the cervical spine (Figs $2 a, b$ ).

\section{Histological findings of the resected ligamentum flavum}

All resected specimens showed calcium deposition diffusely scattered within the ligamentum flavum. No particular site of deposition predominated but, in case 5, a large mass located at the L3-4 level on the right had compressed both the L4 and L5 roots ipsilaterally. The ligamentum flavum revealed no marked adhesion to the neural tissue in any case, and was easily removed during surgery. No calcium deposition was noted in the dura mater of the nerve root sleeves. Histologically, the ligament showed a slight thickening containing diffuse calcium granules but no granulomatous or inflammatory changes were evident (Figure 3). A small number of fibroblasts was observed around the calcium granules. Histology confirmed that the ligamentum flavum had not ossified.

\section{Energy dispensive radiographic microanalysis}

Calcium pyrophosphate dihydrate (CPPD) was identified in crystals in all cases, and hydroxyapatite was also observed in three patients. Calcium orthophosphate was identified in one case and unknown crystals were observed in another.

\section{Discussion}

The number of reports of lumbar spinal stenosis is increasing and the disease is becoming better understood as the knowledge from basic investigations and clinical research accumulates. The ligamentum flavum, in association with the hypertrophied facet joints intraspinally, may play an important role in entrapping the dural sac and the nerve roots at this origin from the

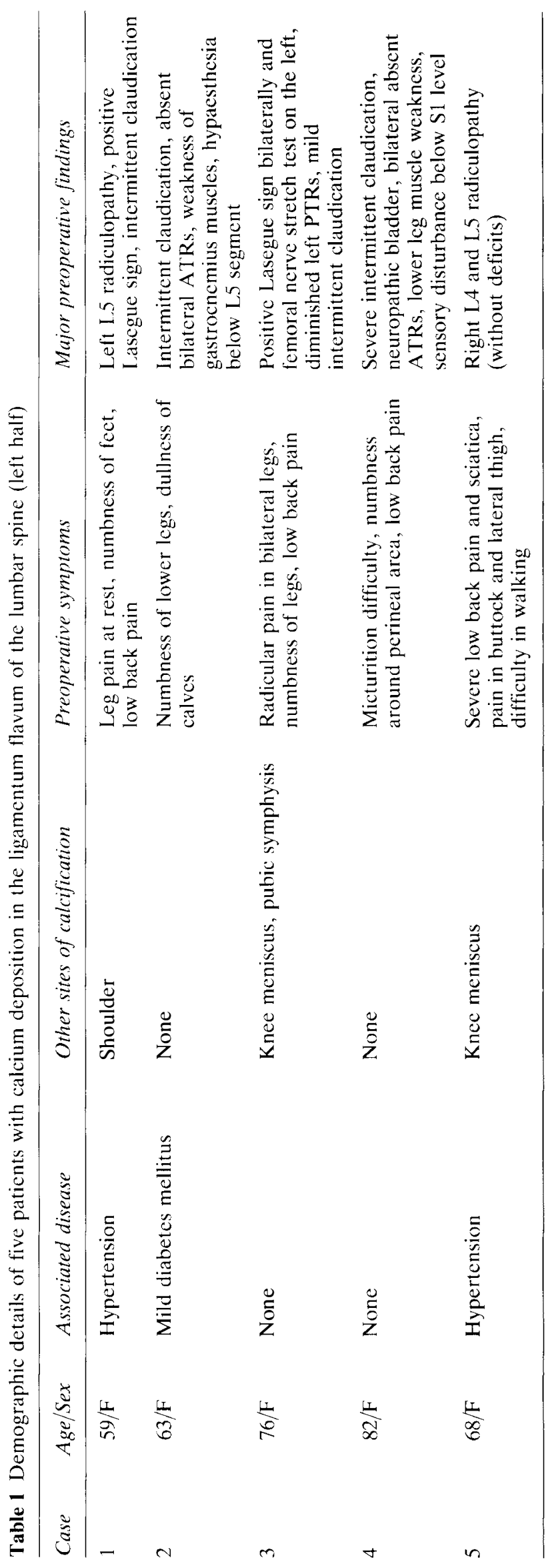


Table 2 Demographic details of five patients with calcium deposition in the ligamentum flavum of the lumbar spine (right half)

\begin{tabular}{|c|c|c|c|c|c|}
\hline $\begin{array}{l}\text { Spinal levels and types of } \\
\text { calcification }\end{array}$ & $\begin{array}{l}\text { Class of stenotic } \\
\text { status }^{a}\end{array}$ & Deposited crystal & Treatment & $\begin{array}{l}\text { Period observed } \\
\text { postoperatively } \\
\text { (years) }\end{array}$ & Results \\
\hline $\begin{array}{l}\text { L4-5, L5-S1 (diffuse, } \\
\text { massive) }\end{array}$ & $\begin{array}{l}\text { Degenerative } \\
\text { scoliosis }\end{array}$ & $\underset{\mathrm{COP}}{\mathrm{CPPD}}+\mathrm{HAP}+$ & Laminectomy (L5) & 7.0 & Good \\
\hline L4-5 (diffusely scattered) & $\begin{array}{l}\text { Degenerative } \\
\text { spondylolisthesis }\end{array}$ & CPPD & Laminectomy (L5) & 6.3 & Excellent \\
\hline L4-5 (diffuse) & Degenerative & $\mathrm{CPPD}+\mathrm{HAP}$ & $\begin{array}{l}\text { Partial laminectomy } \\
\quad(\mathrm{L} 4-5)\end{array}$ & 2.1 & Good \\
\hline L4-5, L5-S1 (massive) & $\begin{array}{l}\text { Degenerative } \\
\text { spondylolisthesis }\end{array}$ & $\mathrm{CPPD}+\mathrm{HAP}$ & Laminectomy (L5) & 1.5 & Fair \\
\hline $\begin{array}{l}\text { L3-4, L4-5 (diffuse, } \\
\text { massive in part) }\end{array}$ & Degenerative & $\begin{array}{l}\text { CPPD + unknown } \\
\text { calcium }\end{array}$ & Laminectomy (L4) & 0.8 & Excellent \\
\hline
\end{tabular}

${ }^{a}$ According to the classification of Arnoldi et al ${ }^{6}$ b CPPD, calcium pyrophosphate dihydrate; HAP, hydroxyapatite; COP, calcium orthophosphate

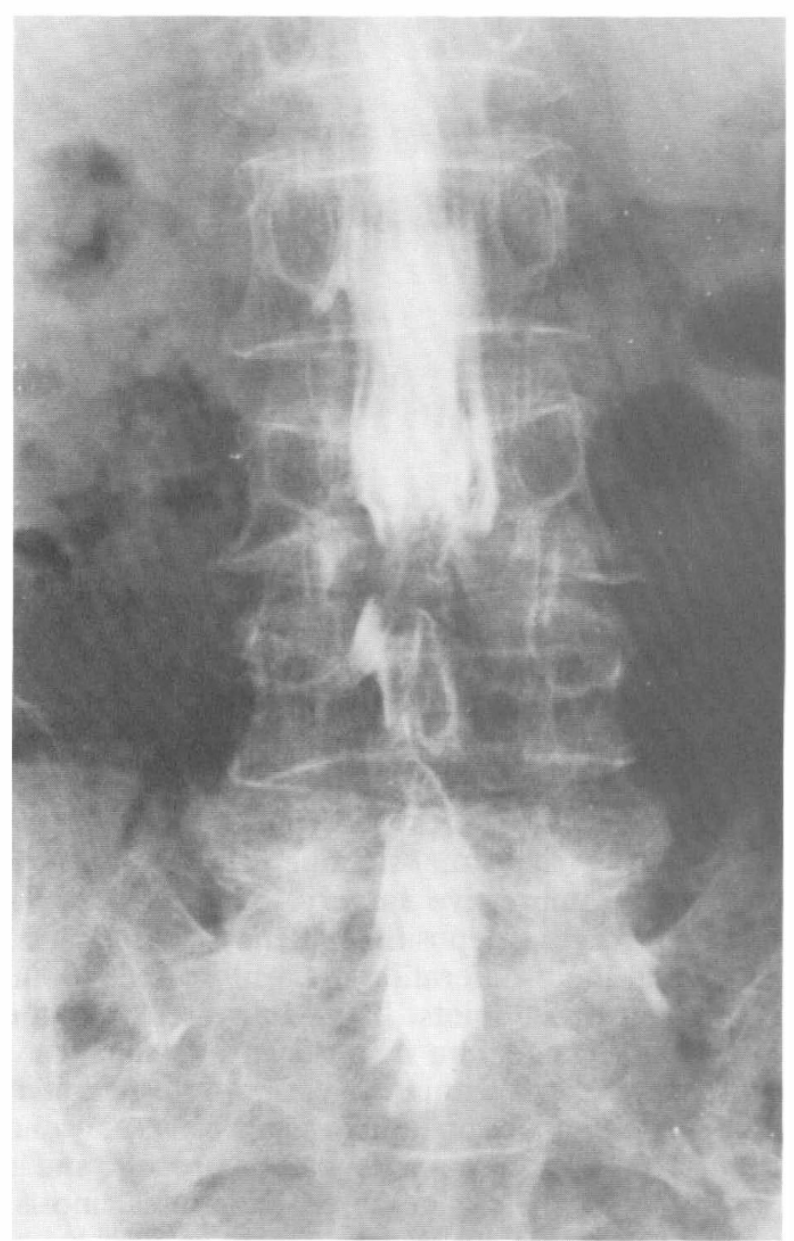

Figure 1 Typical myelographic appearance showing the hour-glass constriction of the dural sac in a patient with degenerative stenosis at L3-4 and L4-5 (case 5)

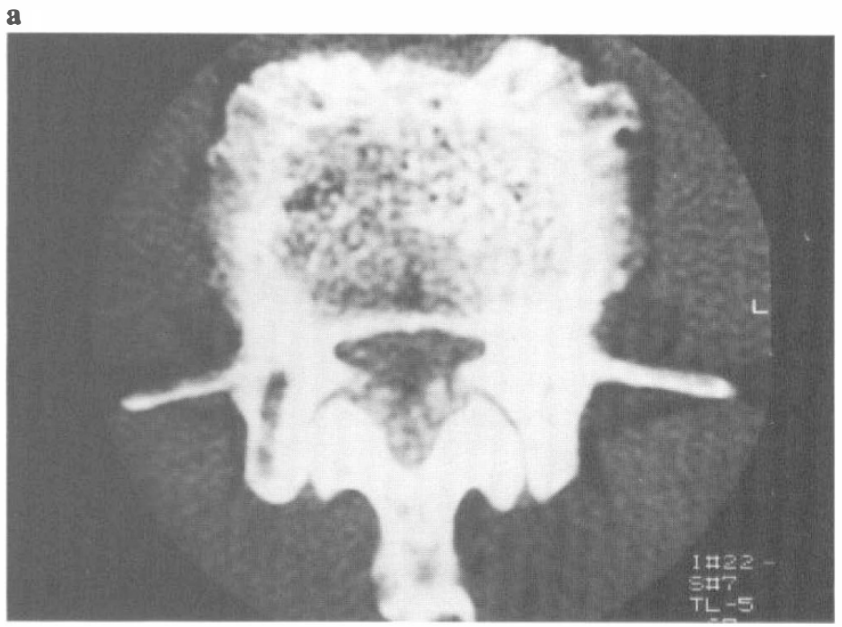

b

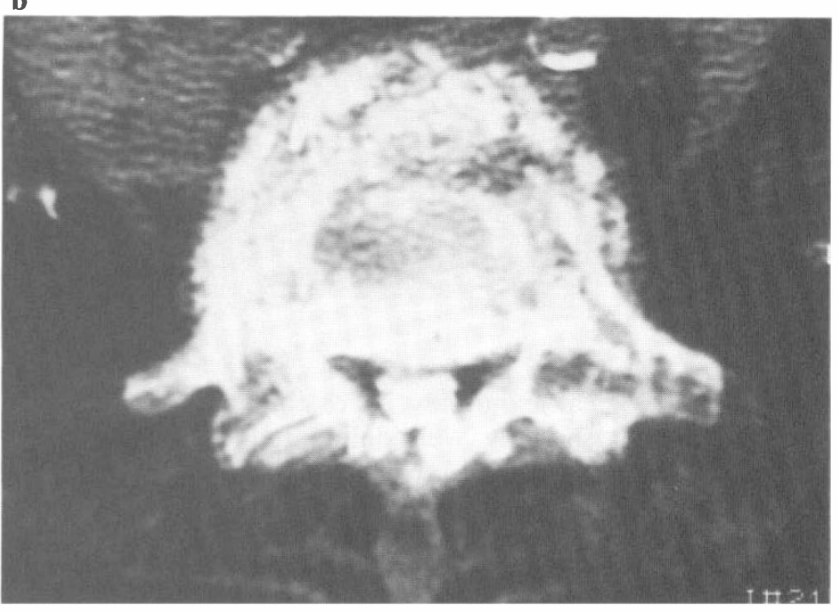

Figure 2 Computed tomography myelography showing diffusely deposited calcium in the ligamentum flavum (a) in case 2 and massively nodular deposition (b) in case 4 


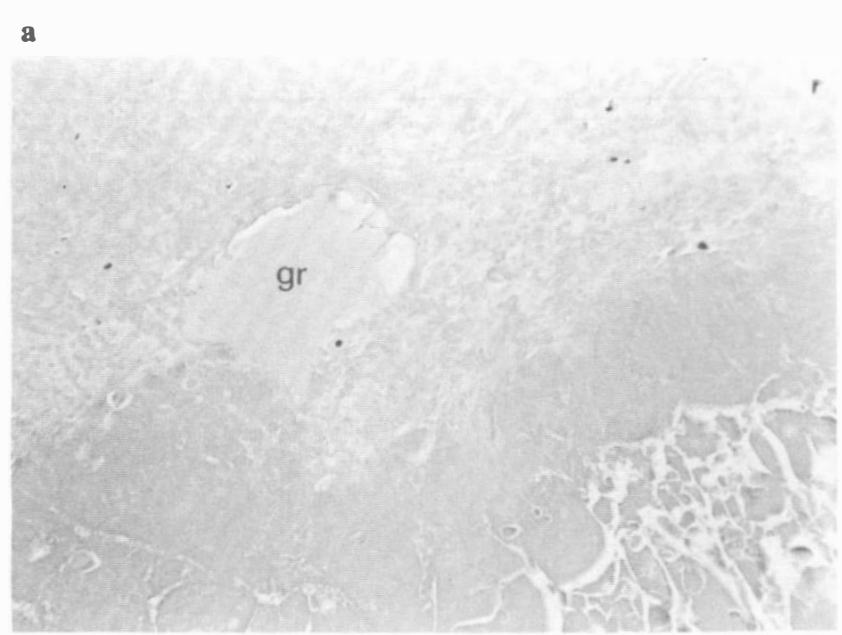

b

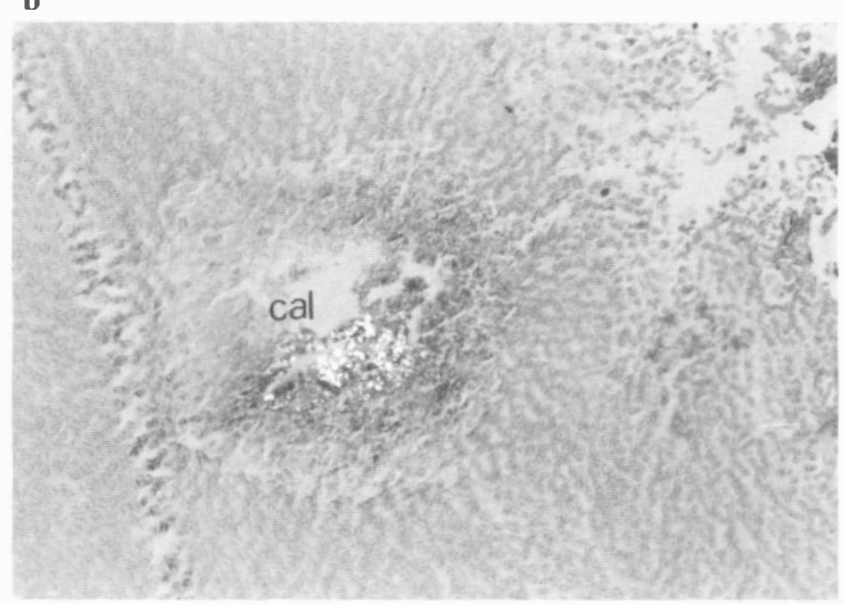

c

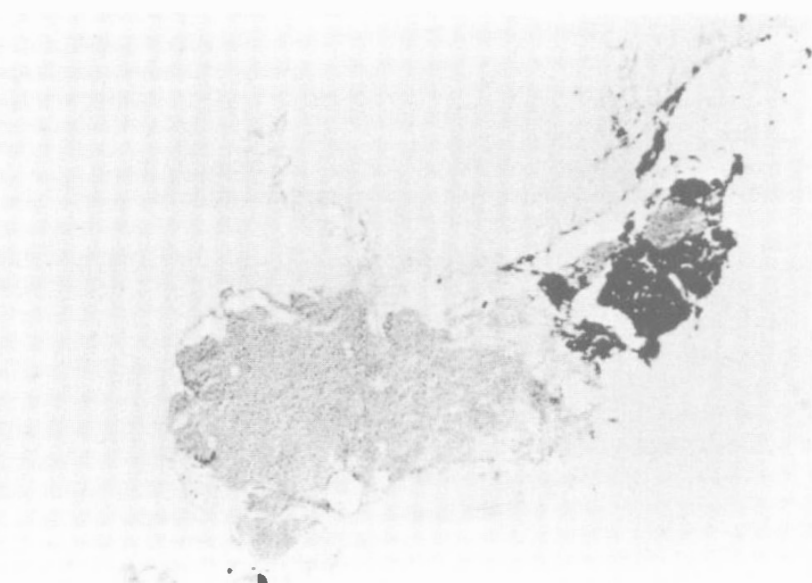

Figure 3 Histological examples of calcium deposition. (a) Photomicrograph showing well delineated calcium deposition within the granulative area of the ligament demonstrating marked degenerative changes (gr, granulation; haematoxylin and eosin stains, $\times 30$ objective). (b) Photomicrograph showing calcium crystals identifiable within the granulative area of the ligament (cal, calcium crystals; haematoxylin and eosin stains with polarized light, $\times 30$ objective). (c) Photomicrograph showing the deposits as calcium (von Kossa's stain, $\times 20$ objective) theca. However, the possible role of calcification within the degenerated ligamentum flavum producing neurological compromise must not be neglected. ${ }^{9,8}$ Most reports focus on the facet and neuroforaminal morphology in conjunction with neural tissue compression. Recently, Schröder et $a l^{9}$ studied the histological process and calcification of the ligamentum flavum obtained from 21 surgical cases operated on for symptomatic lumbar spinal stenosis. They observed that nearly all of the ligaments were calcified: on the average, $0.17 \%$, with a maximum of $3.8 \%$ in the size of the entire ligament. In comparison with controls, they concluded that calcium deposition within the ligament significantly increased the symptoms, and suggested that such deposits may play an important role in spinal stenosis. Unlike the situations in the cervical and thoracic spine, ${ }^{10}$ symptomatic ossification of the ligamentum flavum in the lumbar spine appears to be rare. Nakamura et al, ${ }^{11}$ however, studied the ossification process of the ligament histologically and reported that microscopic ossification and chondroblasts were more frequently observed. From their findings, they concluded that the unstable lumbar spine accelerates degeneration and chondrometaplasia of the ligamentum flavum. These findings may be true histologically but, in the clinical situation, ossification of the ligamentum flavum in the lumbar spine appears to be a rare occurrence; similarly to the experience of others, our clinical observations ${ }^{12-15}$ suggested that ossification of the spinal ligaments mainly involves the cervical and thoracic areas. Why the lumbar ligamentum flavum rarely ossifies has been the subject of enthusiastic investigation.

From electron microscopic and radiographic diffraction studies on calcium deposition in the cervical ligamentum flavum, Kawano et al $^{16}$ postulated that a nodular type of calcium deposit containing a chemically unstable form of CPPD is transformed finally to a linear one composed of stable hydroxyapatite. Kubota et $a^{17}$ observed extracellular plasma membraneinvested matrix vesicles and thick wall-bound matrix giant bodies within the calcified ligamentum flavum, and concluded that these vesicles and bodies precipitate minerals which eventually coalesce to form calcified nodules. These matrix vesicles are believed to originate from degenerated fibroblasts. Yoshida et al, ${ }^{18}$ conducting an immunohistochemical study on the ligamentum flavum obtained from canal-stenotic patients undergoing lumbar decompressive surgery, observed histological calcium crystal deposition in the hypertrophied ligaments and the proliferation of cartilage cells in the vicinity of the facet joints. They suggested that the hypertrophied ligamentum flavum, with its significant degenerative changes within the elastic fibres containing abundant numbers of foreign giant cells, plays an important role in the calcium deposition process, and is possibly influenced by generalized chondrocalcinosis. Schröder et $a l^{9}$ maintain that the increase in calcium crystals is one of the main reasons for thickening of the ligamentum flavum. Although current observations do not advance the study of the process of calcium 
deposition, it may be suggested that significant degenerative changes in the elastic fibres with thickening of the ligament itself may be associated with this pathological condition.

Calcification of the ligamentum flavum may be associated with certain generalized diseases such as chondrocalcinosis or systemic calcium crystal deposition disease. ${ }^{19-22}$ Watanabe et $a l^{23}$ reported that a $17 \%$ incidence of calcification was noted in the cervical ligamentum flavum in 30 patients with a pseudogout syndrome of the knee. Factors such as aging, metabolic disorders, and hormonal imbalance, which affect ligamentous degeneration, may precipitate general calcification. Our previous report ${ }^{24}$ on the calcified cervical ligamentum flavum concerns a positive correlation between the crystal deposition and systemic disease but the limited number of patients in our current series does not permit a definitive statement regarding the possible aetiology. Symptomatic deposition is removed surgically. However, as Takehara et $a^{25}$ suggested, the lesion may be reduced in size or even absorbed by the administration of etane-1-hydroxy-1-diphosphate. Asymptomatic calcium deposition at other sites in the operative area can be treated by the prophylactic use of this drug.

We concluded that symptoms such as lumbar spinal stenosis may be accelerated by coexisting calcium crystal deposition within the ligamentum flavum at the affected spinal levels. Although the calcium lesion may be less important than are the hypertrophied facet joint in producing symptoms, it appears to play a role in advancing the disease by increasing the thickness and consistency of the degenerated ligamentum flavum.

\section{References}

1 Grauer W. Die radiologische Abklärung der degenerativen lumbalen Stenose. Orthopäde 1993; 22: 214-222.

2 Grob D, Humke T, Dvorak J. Die Bedeutung der simultanen Fusion bei operativer Dekompression der lumbalen Spinalstenose. Orthopäde 1993; 22: 243-249.

3 Bullough PG, Boachie-Adjei O. Deposition disease of the spine. In: Bullough PG, Boachie-Adjei O, (eds). Atlas of Spinal Diseases. JB Lippincott: Philadelphia, 1988; pp 68-75.

4 Muto Y, Tajima K, Yamakawa N. A case report of lumbar spinal stenosis caused by calcification of the ligamenta flava. Clin Orthop Surg (Tokyo) 1990; 25: 627-629.

5 Kurihara A, Tanaka Y, Tsumura N, Iwasaki Y. Hyperostotic lumbar spinal stenosis: a review of 12 surgically treated cases with roentgenographic survey of ossification of the yellow ligament at the lumbar spine. Spine 1988; 13: 1308-1316.

6 Arnoldi CC et al. Lumbar spine stenosis and nerve root entrapment syndrome; definition and classification. Clin Orthop 1976; 115: 4-5.

7 Resnick D, Pineda C. Vertebral involvement in calcium pyrophosphate dihydrate crystal deposition disease. Radiology 1984; 153: 55-60.

8 Yahia LH, Garzon S, Strykowski H, Rivard CH. Ultrastructure of the human intraspinous ligament and ligamentum flavum: a preliminary study. Spine 1990; 15: 262-268.

9 Schröder P, Grob D, Rahn BA. Histologische Veranderungen des Lig. Flavum bei Patienten mit Spinalkanalstenose. Orthopäde 1993; 22: 223-226.

10 Kubota M, Baba I, Sumida T. Myelopathy due to ossification of the ligamentum flavum of the cervical spine: a report of two cases. Spine 1981; 6: 553-559.

11 Nakamura $\mathrm{T}$ et al. Degeneration and ossification of the yellow ligament in unstable spine. J Spinal Disord 1990; 3: 288-292.

12 Tomita $\mathrm{K}$, Nomura S, Umeda S, Baba $\mathrm{H}$. Cervical laminoplasty to enlarge the spinal canal in multilevel ossification of the posterior longitudinal ligament with myelopathy. Arch Orthop Trauma Surg 1988; 107: 148-153.

13 Tomita $\mathrm{K}$ et al. Circumspinal decompression for thoracic myelopathy due to ossification of the posterior longitudinal ligament and ligamentum flavum. Spine 1990; 15: 1114-1120.

$14 \mathrm{Baba} \mathrm{H}$ et al. Spinal cord evoked potentials in thoracic myelopathy with multisegmental vertebral involvement. Spine 1992; 17: 1291-1295.

15 Baba H, Kawahara N, Tomita K, Imura S. Spinal cord evoked potentials in cervical and thoracic myelopathy. Int Orthop 1993; 17: $82-86$.

16 Kawano $\mathrm{N}$ et al. Calcium pyrophosphate dihydrate crystal deposition disease in the cervical ligamentum flavum. $J$ Neurosurg 1988; 68: 613-620.

17 Kubota $\mathrm{T}$ et al. Ultrastructural study of calcification process in the ligamentum flavum of the cervical spine. Spine 1986; 12: 317-323.

18 Yoshida $\mathrm{M}$ et al. Hypertrophied ligamentum flavum in lumbar spinal canal stenosis: pathogenesis and morphologic and immunohistochemical observation. Spine 1992; 17: 1353-1360.

19 Doherty M, Dieppe P. Crystal deposition disease in the elderly. Clin Rheum Dis 1986; 12: 97-117.

20 Hamilton EBD. Diseases associated with CPPD deposition disease. Arthritis Rheum 1976; 19: 353-357.

21 Lust $\mathrm{G}$ et al. Evidence of a generalized metabolic defect in patients with hereditary chondrocarcinosis: increased inorganic pyrophosphate in cultured fibroblasts and lymphoblasts. Arthritis Rheum 1981; 24: 1517-1521.

22 McCarty DJ. Calcium pyrophosphate dihidrate crystal deposition disease: nomenclature and diagnostic criteria. Ann Intern Med 1977; 87: 240-242.

23 Watanabe $\mathrm{W}$ et al. Radiological study on calcification of the ligamentum flavum of the cervical spine. Clin Orthop Surg (Tokyo) 1977; 25: 1006-1011.

$24 \mathrm{Baba} \mathrm{H}$ et al. Calcium crystal deposition in the ligamentum flavum of the cervical spine. Spine 1993; 18: 2174-2181.

25 Takehana T, Shingu H, Shiotani A, Ohhama M. Treatment of calcification of the cervical ligamentum flavum with EHDP. Orthop Surg (Tokyo) 1989; 40: 1543-1545. 